\title{
Circulating vascular endothelial growth factor concentrations in patients with postmenopausal osteoporosis
}

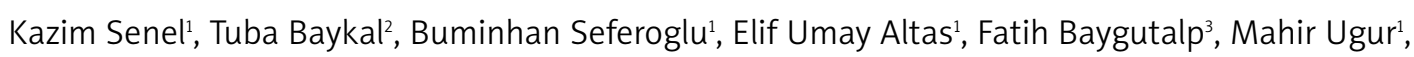 \\ Ahmet Kiziltunc ${ }^{4}$
}

\author{
1Department of Physical Medicine and Rehabilitation, Ataturk University Medicine \\ Faculty, Erzurum, Turkey \\ 2Department of Physical Medicine and Rehabilitation, Batman Regional Hospital, \\ Batman, Turkey \\ ${ }^{3}$ Department of Physical Medicine and Rehabilitation, Erzurum Regional Education \\ and Research Hospital, Erzurum, Turkey \\ ${ }^{4}$ Department of Biochemistry, Ataturk University Medicine Faculty, Erzurum, Turkey
}

Submitted: 8 February 2012

Accepted: 15 July 2012

Arch Med Sci 2013; 9, 4: 709-712

DOI: 10.5114/aoms.2013.36896

Copyright (c) 2013 Termedia \& Banach
Corresponding author: Prof. Dr. Kazim Senel Atatürk University University loj. 55-7

25240 Erzurum, Turkey Phone: +90 5326774937

Fax: +904422361301

E-mail: kazimsenel@gmail.com

\begin{abstract}
Introduction: The role of vascular endothelial growth factor (VEGF) in osteoporosis has not yet been clearly established. Vascular endothelial growth factor is an important part of bone formation. In the literature, although the effects of VEGF on bone metabolism were investigated by different studies, there are very rare studies analysing the association between osteoporosis and VEGF. In the present study, our objective was to investigate serum VEGF concentrations in patients with postmenopausal osteoporosis (PMO) and the correlation of serum VEGF levels and bone mineral density (BMD).

Material and methods: This study was performed on 35 PMO patients, and 30 age-matched healthy controls. Serum VEGF concentrations were measured using a quantitative sandwich enzyme immunoassay technique according to the manufacturer's instructions. Bone mineral density values were determined by dual energy X-ray absorptiometry (DEXA).

Results: Serum VEGF concentrations were statistically significantly lower in PMO patients than in controls $(150 \pm 65 \mathrm{pg} / \mathrm{ml}, 260 \pm 135 \mathrm{pg} / \mathrm{ml}$ respectively; $p=0.005)$. A positive correlation was found between serum VEGF concentrations and BMD values $(r=0.63, p=0.001)$.

Conclusions: Vascular endothelial growth factor concentrations were decreased in PMO patients and VEGF may play an important role in bone health.
\end{abstract}

Key words: post-menopausal osteoporosis, vascular endothelial growth factor.

\section{Introduction}

The role of vascular endothelial growth factor (VEGF) in osteoporosis (OP) has not yet been clearly established [1-3]. Vascular endothelial growth factor is an important part of bone formation. Also, angiogenesis is a crucial part of bone formation [4]. Recent studies have suggested that VEGF is a potent angiogenic stimulator, and it may play an important role during endochondral bone formation in hypertrophic cartilage remodelling, ossification, and angiogenesis. Hypertrophic chondrocytes express VEGF 
in vivo and osteoblastic cells express VEGF and its receptors in vitro. However, VEGF can induce migration and differentiation of osteoblastic cells [4-6]. In addition, VEGF was shown to stimulate the formation, survival and resorption activity of osteoclasts in vitro $[4,7]$.

Vascular endothelial growth factor was first described as tumour vascular permeability factor (VPF) in 1983 but was finally discovered and characterized in 1989 [8]. Vascular endothelial growth factor is a homodimeric, heavily glycosylated protein of 46-48 kDa [2]. There are several isoforms of human VEGF $[2,8]$.

The role of VEGF in various diseases including diabetic retinopathy, end stage renal disease, rheumatoid arthritis, giant cell arteritis, and breast cancer has been investigated in several studies [9-11]. In the present study, serum VEGF levels in patients with postmenopausal osteoporosis (PMO) were determined and the relationship between VEGF and bone mineral density (BMD) was evaluated. We discuss the possible role of VEGF in PMO patients.

\section{Material and methods}

Thirty-five post-menopausal women fulfilling OP diagnostic criteria of the World Health Organization (WHO) and 30 post-menopausal healthy women without OP were included in this study. Patients with secondary osteoporosis and systemic diseases were excluded by means of laboratory and radiological findings. Bone mineral density values were measured by dual energy X-ray absorptiometry (DEXA) at lumbar, femoral neck and total hip regions. All scans and analyses were performed by

Table I. Demographic data, clinical, radiological and laboratory features of the patients and controls

\begin{tabular}{|c|c|c|c|}
\hline Parameter & $\begin{array}{l}\text { Controls } \\
(n=30)\end{array}$ & $\begin{array}{l}\text { Patients } \\
(n=35)\end{array}$ & Value of $p$ \\
\hline Age [year] & $65.6 \pm 6.8$ & $66.2 \pm 7.5$ & $>0.05$ \\
\hline $\begin{array}{l}\text { Age of menarche } \\
\text { [year] }\end{array}$ & $13.7 \pm 1.3$ & $13.5 \pm 1.2$ & $>0.05$ \\
\hline $\begin{array}{l}\text { Number of } \\
\text { pregnancies }\end{array}$ & $3.4 \pm 1.8$ & $3.6 \pm 1.7$ & $>0.05$ \\
\hline $\begin{array}{l}\text { Duration of } \\
\text { menopause [year] }\end{array}$ & $17 \pm 2.6$ & $18 \pm 2.4$ & $>0.05$ \\
\hline $\mathrm{BMI}\left[\mathrm{kg} / \mathrm{m}^{2}\right]$ & $29.8 \pm 4.9$ & $27.6 \pm 4.3$ & $>0.05$ \\
\hline $\begin{array}{l}\text { BMD T scores } \\
{\left[\mathrm{g} / \mathrm{cm}^{2}\right]}\end{array}$ & $0.2 \pm 1.1$ & $-3.2 \pm 0.7$ & $<0.01$ \\
\hline $\begin{array}{l}\text { BMD Z scores } \\
{\left[\mathrm{g} / \mathrm{cm}^{2}\right]}\end{array}$ & $0.5 \pm 1.2$ & $-2.4 \pm 0.6$ & $<0.01$ \\
\hline VEGF $[\mathrm{pg} / \mathrm{ml}]$ & $260 \pm 135$ & $150 \pm 065$ & $<0.01$ \\
\hline
\end{tabular}

$B M I$ - body mass index, $B M D$ - bone mineral density, VEGF-vascular endothelial growth factor the same technician. The 30 post-menopausal healthy women without OP were taking no medications known to affect bone metabolism and had no inflammatory or infectious diseases included as exclusion criteria for the control and patient group. Patients had no vertebral, hip or distal forearm fractures as a result of osteoporosis.

We measured circulating levels of VEGF in the serum of 35 osteoporotic and 30 healthy postmenopausal women. All blood samples were taken from PMO patients and control subjects in the morning after an overnight fast. Sera were collected by centrifugation of 1500/s for $15 \mathrm{~min}$ and stored at $-70^{\circ} \mathrm{C}$ until the time of analysis. Serum VEGF levels were determined by using a quantitative sandwich enzyme immunoassay technique according to the manufacturer's instructions. The demographic data, the clinical characteristics, the examination findings and DEXA results were recorded in PMO patients and control subjects.

\section{Statistical analysis}

Statistical analyses were performed with the SPSS statistics package. All data were expressed as mean \pm SD. Data analysis was performed using Mann-Whitney $U$ test. Pearson correlation test was used to evaluate the correlations between VEGF levels and BMD results. Values of $p$ less than 0.05 were accepted as significant.

\section{Results}

Table I shows the demographic data and clinical characteristics of the patients and controls. There was no statistically significant difference between the groups with respect to age, age of menarche, number of pregnancies, duration of menopause, and body mass index (BMI) results $(p>0.05)$.

Vascular endothelial growth factor serum levels were statistically significantly lower $(p=0.005)$ in patients with PMO $(150 \pm 65 \mathrm{pg} / \mathrm{ml})$ than in controls $(260 \pm 135 \mathrm{pg} / \mathrm{ml})$. A positive correlation was found between serum VEGF concentrations and BMD T scores $(r=0.63, p=0.001)$ and $Z$ scores $(r=0.54$, $p<0.01)$. There was no correlation between VEGF and age, $\mathrm{BMI}$, or menopause duration in $\mathrm{PMO}$ patients.

\section{Discussion}

In the literature, although the effects of VEGF on bone metabolism have been investigated by different studies, there are few studies analysing the association between osteoporosis and VEGF $[1-3,12,13]$. The role of VEGF in PMO is controversial [14-16].

There are some studies reporting decreased VEGF levels in osteoporosis [2, 12]. It has been suggested that VEGF is produced in osteoblasts and its concentrations are decreased in patients with 
osteoporosis. The reduction in VEGF levels correlated with the measurement of BMD. Vascular endothelial growth factor concentrations were $60 \%$ lower $(p<0.001)$ in osteoporosis patients $[2,12]$. Martinez et al. observed an age-related decrease in the secreted levels of VEGF in osteoblasts [17]. They suggested that VEGF may be an important modulating factor for bone remodelling in PMO patients.

In the present study, we postulated that VEGF concentrations would be reduced in PMO patients. We investigated the VEGF levels and their association with $\mathrm{BMD}$ in $\mathrm{PMO}$ patients. Vascular endothelial growth factor levels were found lower in PMO patients than control subjects and positive correlations were determined between VEGF levels and $B M D$ values. In contrast, there are striking studies regarding the possible association of increased VEGF activity and osteoporosis $[13,18]$. It was reported that in mice oestrogen insufficiency led to osteoblastic bone loss due to an increase in the VEGF production of bone tissue $[13,18]$. Harada et al. vascular endothelial growth factor detected expression of VEGF in human osteoblasts and they showed that prostaglandin $E_{2}$ increased VEGF mRNA levels [19]. Costa et al., in 252 post-menopausal women, determined BMD, serum oestradiol and VEGF levels. They observed no significant difference in serum VEGF concentrations between cases and controls [3]. Similarity, Cebi et al. investigated the relation between serum VEGF levels and BMD values and the role of VEGF in aetiopathogenesis of osteoporosis [1]. Their results showed that plasma VEGF levels of osteoporotic subjects were higher than in the normal group, although the difference was not statistically significant. In the present study, our results are in line with the studies of Pufe et al. [2]. We think that the decrease in VEGF levels in PMO patients may also be the results of medications, genetic, environmental and endocrine factors. However, we excluded patients taking medications that may affect bone metabolism and we did not assess the effect of environmental factors and considering genetic factors we did not study the polymorphism. Several hormones have been shown to regulate VEGF production locally [3, 20]. Oestrogen has been shown to regulate VEGF gene transcription [20]. Glucocorticoids inhibit COX-2 and $\mathrm{PGE}_{2}$ production. Because $P G E_{2}$ is able to increase VEGF synthesis, this may be a link between GC and VEGF decrease and $P G E_{2}$ is able to increase VEGF synthesis [2]. Oestrogen increases vitamin $D$ receptors on the duodenal mucosa. 1,25 dihydroxyvitamin D increases the release of VEGF. This may explain the anabolic effects of VEGF on bone metabolism [21].

Several studies have shown that two common functional polymorphisms are associated with VEGF production $[22,23]$. The $936 \mathrm{~T}$ allele has been associated with lower production of VEGF [22]. A sig- nificant correlation was observed between VEGF protein production and genotype for the +405 polymorphism [23]. Previous studies have shown significant associations between VEGF levels and this polymorphism in healthy males and postmenopausal women [22, 24]. However, previous reports have demonstrated that individuals with a $634 \mathrm{C}$ allele are predisposed to disorders where enhanced VEGF expression may play a role in disease progression such as diabetic retinopathy, giant cell arteritis, and breast cancer [3]. Moreover, a study analysing 252 post-menopausal women reported no significant difference in serum VEGF concentrations between cases and controls [25].

In conclusion, our results demonstrated that VEGF concentrations were decreased in PMO patients compared to controls and VEGF may play an important role in bone metabolism. However, VEGF levels may be influenced by genetic, environmental and endocrine factors. Further studies on the role of VEGF in PMO patients will be helpful to clarify the aetiopathogenesis and treatment of PMO.

\section{References}

1. Cebi H, Aksahin E, Yuksel HY, Celebi L, Aktekin CN, Hapa O. Plasma vascular endothelial growth factor levels are similar in subjects with and without osteoporosis. Eklem Hastalik Cerrahisi 2010; 21: 91-7.

2. Pufe T, Scholz-Ahrens KE, Franke AT, et al. The role of vascular endothelial growth factor in glucocorticoidinduce bone loss: evaluation in a minipig model. Bone 2003; 33: 869-76.

3. Costa N, Paramanathan S, Mac Donald D, Wierzbicki AS, Hampson C. Factors regulating circulating vascular endothelial growth factor (VEGF): association with bone mineral density (BMD) in post-menopausal osteoporosis. Cytokine 2009; 46: 376-81.

4. Maes C, Carmeliet P, Moermans K, et al. Impaired angiogenesis and endochondral bone formation in mice lacking the vascular endothelial growth factor isoforms VEGF 164

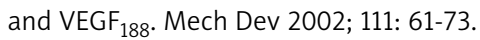

5. Gerber HP, Vu TH, Ryan AM, Kowalski J, Werb Z, Ferrara N. VEGF couples hypertrophic cartilage remodeling, ossification and angiogenesis during endochondral bone formation. Nat Med 1999; 5: 623-8.

6. Deckers MM, Karperien M, van der Bent C, Yamashita T, Papapoulos SE, Löwik CW. Expression of vascular endothelial growth factors and their receptors during osteoblast differentiation. Endocrinology 2000; 141: 1667-74.

7. Nakagawa M, Kaneda T, Arakawa T, et al. Vascular endothelial growth factor (VEGF) directly enhances osteoclastic bone resorption and survival of mature osteoclasts. FEBS Lett 2000; 473: 161-4.

8. Keramaris NC, Calori GM, Nikolaou VS, Schemitsch EH, Giannoudis PV. Fracture vascularity and bone healing; a systematic rewiev of the role of VEGF. Injury 2008; 39 Suppl 2: 545-57.

9. Bączyk G, Opala T, Kleka P, Chuchracki M. Multifactorial analysis of risk factors for reduced bone mineral density among postmenopausal women. Arch Med Sci 2012; 8: 332-41. 
10. Yazici S, Korkmaz U, Erkan M, et al. The effect of breastfeeding duration on bone mineral density in postmenopausal Turkish women: a population-based study. Arch Med Sci 2011; 7: 486-92.

11. Bergler-Czop B, Brzezińska-Wcisło L, Syguła E. Evaluation of the nailfold skin capillaroscopic modifications of psoriatic patients and levels of the transforming growth factor and vascular endothelial growth factor: an initiative paper. Postep Derm Alergol 2011; 28: 428-34.

12. Pufe T, Claassen H, Scholz-Ahrens KE, et al. Influence of estradiol on vascular endothelial growth factor expression in bone: a study in Gottingen miniature pigs and human osteoblasts. Calcif Tissue Int 2007; 80: 184-91

13. Kodama I, Niida S, Sanada M, et al. Estrogen regulates the production of VEGF for osteoclast formation and activity in op/op mice. J Bone Miner Res 2004; 19: 200-6.

14. Karwowski W, Naumnik B, Szczepański M, Myśliwiec M. The mechanism of vascular calcification - a systematic review. Med Sci Monit 2012; 18: 1-11.

15. Panico A, Lupoli GA, Marciello F, et al. Teriparatide vs. alendronate as a treatment for osteoporosis: changes in biochemical markers of bone turnover, BMD and quality of life. Med Sci Monit 2011; 17: 442-8.

16. Sypniewska G, Sobanska I, Pater A, Kedziora-Kornatowska K, Nowacki W. Does serum osteoprotegerin level relate to fragility fracture in elderly women with low vitamin D status? Med Sci Monit 2010; 16: 96-101.

17. Martínez $P$, Esbrit $P$, Rodrigo A, Alvarez-Arroyo MV, Martínez ME. Age-related changes in parathyroid hormone-related protein and vascular endothelial growth factor in human osteoblastic cells. Osteoporos Int 2002; 13: 874-81.

18. Niida S, Kaku M, Amano H, et al. Vascular endothelial growth factor can substitute for macrophage colonystimulating factor in the support of osteoclastic bone resorption. J Exp Med 1999; 190: 293-8.

19. Harada S, Nagy JA, Sullivan KA, et al. Induction of vascular endothelial growth factor expression by prostaglandin E2 and E1 in osteoblasts. J Clin Invest 1994; 93: 2490-6.

20. Hyder SM, Nawaz Z, Chiappetta C, Stancel GM. Identification of functional estrogen response elements in the gene coding for the potent angiogenic factor vascular endothelial growth factor. Cancer Res 2000; 60: 3183-90.

21. Wang DS, Miura M, Demura H, Sato K. Anabolic effects of 1,25-dihydroxyvitamin D3 on osteoblasts are enhanced by vascular endothelial growth factor produced by osteoblasts and by growth factors produced by endothelial cells. Endocrinology 1997; 138: 2953-62.

22. Renner W, Kotschan S, Hoffmann C, Obermayer-Pietsch B, Pilger E. A common $936 \mathrm{C} / \mathrm{T}$ mutation in the gene for vascular endothelial growth factor is associated with vascular endothelial growth factor plasma levels. J Vasc Res 2000; 37: 443-8.

23. Watson CJ, Webb NJ, Bottomley MJ, Brenchley PE. Identification of polymorphisms within the vascular endothelial growth factor (VEGF) gene: correlation with variation in VEGF protein production. Cytokine 2000; 12: 1232-5.

24. Krippl P, Langsenlehner U, Renner W, et al. A common $936 \mathrm{C} / \mathrm{T}$ gene polymorphism of vascular endothelial growth factor is associated with decreased breast cancer risk. Int J Cancer 2003; 106: 468-71.

25. Costa N, Paramanathan S, Mac Donald D, Wierzbicki AS, Hampson G. Factors regulating circulating vascular endothelial growth factor (VEGF): association with bone mineral density (BMD) in post-menopausal osteoporosis. Cytokine 2009; 46: 376-81. 